Felig, P., Owen, O. E., Wahren, J., and Cahill, G. F., jun. (1969). fournal of Clinical Investigation, 48, 584

Gamble, J. L. (1954). Chemical Anatomy, Physiology and Pathology of Extracellular Fluid, 6th Edn. Cambridge, Massachusetts, Harvard Extracellular Fluid,

Kirk, J., Orr, J. S., and Hope, C. S. (1968). British fournal of Haematology, $15,35$.
Morowitz, H. J. (1966). Fournal of Theoretical Biology, 13, 60.

Orr, J. S., Kirk, J., Gray, K. G., and Anderson, J. R. (1968). British fournal

Owen, O. E., Felig, P., Morgan, A. P., Wahren, J., and Cahill, G. F., jun. (1969). Fournal of Clinical Investigation, 48, 574.

Runcie, J., and Thomson, T. J. (1970). British Medical fournal, 3, 432.

Thomson, T. J., Runcie, J., and Miller, V. (1966). Lancet, 2, 992.

\title{
Controlled Trial of Metoclopramide in the Treatment of Flatulent Dyspepsia
}

\author{
A. G. JOHNSON
}

British Medical fournal, 1971, 2, 25-26

\section{Summary}

A double-blind cross-over trial of metoclopramide (Maxolon) against placebo was undertaken in 42 patients with flatulent dyspepsia. A highly significant difference was found in favour of the active drug $(P<0.01)$. The time at which the drug is given in relation to the meal and onset of symptoms is probably important. It is concluded that metoclopramide is effective in the short-term treatment of these symptoms but should be started only after thorough investigations have excluded more serious disease.

\section{Introduction}

Flatulent dyspepsia is a well-known symptom complex occurring in association with cholelithiasis when it may persist after cholecystectomy (Maingot, 1956; Bodvall, 1964), but it has been found with equal frequency in patients with a normal cholecystogram (Price, 1963). It has been defined by Rhind and Watson (1968) as follows: "Epigastric discomfort after meals, a feeling of fullness so that tight clothing is loosened, eructation with temporary relief, and regurgitation of sour fluid to the mouth with heartburn." The cause of these symptoms is not known but they are possibly associated with abnormal gastrointestinal motility, leading to regurgitation of duodenal juice into the stomach (Capper et al., 1967) and delayed gastric emptying.

Metoclopramide increases the strength of gastric antral contractions and speeds gastric emptying, when measured radiologically (Kreel, 1970) or by a dye dilution method (Connell and George, 1969); this effect is still observed after vagotomy (Banke, 1968). It appears to relax the duodenal cap (Jacoby and Brodie, 1967) and cause duodenal contractions to follow those of the antrum if they were previously out of phase (Johnson, 1971), and would, therefore, tend to prevent pyloric regurgitation. It acts by enhancing the local effect of acetylcholine on the gastric smooth muscle (Eisner, 1968), and it also has a central antiemetic effect. It would seem, on theoretical grounds, a suitable drug with which to treat flatulent dyspepsia and has been found to be effective in practice in France and in two preliminary trials in Britain (Boisson and Albot, 1966; Trafford et al., 1967; Marshall, 1970). Charing Cross Hospital Medical School, Fulham Hospital, London
W6 8RF

A. G. JOHNSON, F.R.c.s., Lecturer in Surgery

\section{Patients and Methods}

Selection of Patients.-Consecutive patients attending a gastroenterological clinic were admitted to the trial if they complained only of flatulent dyspepsia as defined above. They came from three clinical groups: (1) Those with radiograph negative dyspepsia (normal barium meal and cholecystogram), but including some patients with a small hiatus hernia; (2) Those with persistent flatulent dyspepsia after cholecystectomy; and (3) Those with these symptoms after vagotomy and pyloroplasty or pyloroplasty alone.

Plan of Trial.-A double-blind cross-over trial was devised of metoclopramide against placebo, each patient being used as his own control. Metoclopramide was given as $10-\mathrm{mg}$ tablets three times a day, the placebo and active tablets being given for two weeks each. This comparatively short period was chosen to avoid the natural fluctuation of the symptoms that tends to occur over the months. If patients were already on treatment for the symptoms with drugs other than antacids a week without drugs was allowed before the trial began. Because metoclopramide probably has a fairly short duration of action it was given just before the meal to patients whose symptoms occurred during or soon after the meal (up to 45 minutes), and after the meal to those whose symptoms occurred one hour or more after food. The patient was supplied with separate containers for each of the four weeks.

Method of Assessment.-The flatulent dyspepsia syndrome was divided into nine individual symptoms: belching; full feeling after normal meals; inability to finish meals; abdomen becomes distended, clothes have to be loosened; burning discomfort in epigastrium; burning discomfort in chest (heartburn); bitter fluid in mouth; nausea; and vomiting. The patients were seen before the trial, and each symptom was recorded as absent, mild, or severe. They were asked to note how these symptoms changed each week. They were told that two types of tablet, which looked identical, were being tried to see which was better. At the end of four weeks they were interviewed again and the degree of symptoms during each week was recorded. Finally, they were asked which two weeks were better. Most stated without hesitation that either the first two or the second two weeks were better, but some said that all the weeks were equally good and some that none of the tablets made any difference. Others stated that either the first and fourth or second and third weeks were better, clearly showing no difference between active drug and placebo. A more complicated arbitrary scoring system involving the types of food eaten was abandoned as it was thought to introduce more observer bias. At least once during each week of the trial the patients were told to try some food known to produce symptoms. 


\section{Results and Discussion}

Forty-two patients (29 women and 13 men) aged 18 to 80 (average 45) years completed the trial. The numbers and results in each clinical group are given in Table $\mathbf{I}$. It will be seen from the series as a whole that there is a highly significant difference between the number preferring metoclopramide and those preferring placebo $\left(\chi^{2}=8.3 ; \mathrm{P}<0.01\right)$. If those who benefited from metoclopramide (groups 1 and 2 ) are compared with those who did not (groups 3 and 4) there is also a significant difference $\left(\chi^{2}=6.1 ; \mathrm{P}<0.01\right)$.

TABLE I-Results of Trial by Clinical Diagnosis

\begin{tabular}{r|r|r|c|c|c}
\hline & Total & $\begin{array}{c}\text { Metoclo- } \\
\text { pramide } \\
\text { Better (1) }\end{array}$ & $\begin{array}{c}\text { No Difference } \\
\text { Effecth (2) }\end{array}$ & $\begin{array}{c}\text { Both } \\
\text { Ineffective (3) }\end{array}$ & Placebo \\
Better (4)
\end{tabular}

$\chi^{2}=8.3 ; P<0.01$.

In any situation where subjective criteria are the principle method of assessment it is axiomatic that the first given drug will have the greater effect. In addition, if there is a "carryover" effect this will tend to be greater when the active drug is given first. The randomization in the trial (Table II) was acting slightly against metoclopramide and in favour of the placebo.

TABLE II-Randomization of Metoclopramide and Placebo

\begin{tabular}{|c|c|c|c|c|c|}
\hline Result & & & Total & $\begin{array}{l}\text { Metoclopramide } \\
\text { Given First }\end{array}$ & $\begin{array}{l}\text { Placebo } \\
\text { Given First }\end{array}$ \\
\hline $\begin{array}{l}\text { Metoclopramide better } \\
\text { Placebo better } \\
\text { Both effective } \\
\text { Both ineffective }\end{array}$ & $\begin{array}{l}\cdots \\
\because \\
\cdots\end{array}$ & $\begin{array}{l}\because \\
\because \\
\because\end{array}$ & $\begin{array}{r}26 \\
9 \\
3 \\
4\end{array}$ & $\begin{array}{r}12 \\
4 \\
2 \\
2\end{array}$ & $\begin{array}{r}14 \\
5 \\
1 \\
2\end{array}$ \\
\hline
\end{tabular}

Distribution of Symptoms.-Thirty-three patients complained of flatulence alone, and three of dyspepsia alone. complained of flatulence alone, and three of dyspepsia alone. Heartburn was present in 31 , of whom five had demonstrable hiatus hernia; two patients with hiatus hernia did not experience heartburn. Vomiting was present in only seven patients, so that antiemetic action of the drug was not being tested. It was noticed that all symptoms were affected equally when improvement occurred. It is particularly interesting that heartburn was relieved, as Heitmann and Möller (1970) showed that metoclopramide produced a selective localized action on the resting tone of closure of the oesophagogastric sphincter while relaxation on swallowing was unimpaired.

Side Effects.-Five patients did not complete the trial, one because the symptoms were worse during the first two weeks (on placebo) and four because of drowsiness (on metoclopramide), though in some cases the flatulent dyspepsia was improved. Three other patients complained of drowsiness, one while on the placebo and two while on metoclopramide, but completed the trial. Drowsiness is a known side effect of the drug and may be reduced by halving the dose. Though a dystonic reaction has been reported, it was not encountered during this trial.

Timing of Administration of Drug.-Most patients experienced their symptoms soon after the meal (within three- quarters of an hour), but in others they occurred later and in some there was no fixed relationship with meals. The results classified by the timing of the symptoms (Table III) show that there is a tendency for metoclopramide to be most effective in those whose symptoms occur less than one hour after a meal.

TABLE III-Results classified by Timing of Symptoms after the Meal

\begin{tabular}{|c|c|c|c|c|}
\hline $\begin{array}{l}\text { Time after Meal of } \\
\text { Onset of Symptoms }\end{array}$ & Total & $\begin{array}{c}\text { Metoclopramide } \\
\text { Better }\end{array}$ & No Difference & Placebo Better \\
\hline $\begin{array}{lll}0-\neq \text { hour } & \ldots & \ldots \\
1-1 \text { f hours } & \ldots & \ldots \\
\text { 2-4 hours } & \ldots & \\
\text { Indefinite relationship }\end{array}$ & $\begin{array}{r}28 \\
7 \\
4 \\
3\end{array}$ & $\begin{array}{r}18 \\
4 \\
3 \\
1\end{array}$ & $\begin{array}{l}6 \\
0 \\
0 \\
1\end{array}$ & $\begin{array}{l}4 \\
3 \\
1 \\
1\end{array}$ \\
\hline
\end{tabular}

Pyloric Function.-In 34 of the 42 patients pyloric regurgitation was studied on either a standard barium meal or a pyloric regurgitation test. Twenty-seven (79\%) showed evidence of pyloric regurgitation, $3(9 \%)$ were reported as showing delayed gastric emptying on barium meal and in four (12\%) no regurgitation or delayed emptying was observed.

Placebo Reactors. - The group which found placebo better did not differ significantly from the rest as regards diagnosis, sex ratio, average age (44 years), distribution of symptoms, or pyloric function.

\section{Conclusions}

Metoclopramide is effective in the short-term treatment of flatulent dyspepsia. The long-term effectiveness cannot be judged from this trial, but some of the patients have been on the drug for up to two years and remain symptom-free. Metoclopramide probably acts by speeding gastric emptying and preventing pyloric and gastro-oesophageal regurgitation. As the length of action on gastric motility is relatively short and it takes 5 to 10 minutes to act by mouth it should be given about half an hour before the patients expect to have their symptoms. Combination with atropine-like drugs will inhibit its efect on gastric motility (Jacoby and Brodie, 1967; Eisner, 1968), and combination with phenothiazine derivatives may increase the incidence of side effects.

It cannot be overstressed that treatment with metoclopramide should be started only after a thorough investigation, including barium meal, cholecystogram, and possibly gastroscopy, has excluded more serious disease.

I am grateful to Dr. O. P. W. Robinson, of Beecham Research Laboratories, for supplying the metoclopramide and placebo and to Mr. J. J. Grimshaw for statistical advice.

\section{References}

Banke, L. (1968). Paper read to VIII International Congress of Gastroenterology in Prague.

Bodvall, B. (1964). Acta Chirurgica Scandinavica, Suppl. No. 329

Boisson, J., and Albot, G. (1966). Cahiers du College de Médecine des Hopitaux de Paris, 7, 45.

Capper, W. M., Butler, T. J., Kilby, J. O., and Gibson, M. J. (1967) Lancet, 1, 413.

Connell, A. M., and George, J. D. (1969). Gut, 10, 678.

Eisner, M. (1968). British Medical fournal, 4, 679.

Heitmann, P., and Möller, N. (1970). In Advance Abstracts of 4th World Congress of Gastroenterology, p. 409.

Jacoby, H. I., and Brodie, D. A. (1967). Gastroenterology, 52, 676.

Johnson, A. G. (1971). Gut, 12, 158.

Kreel, L. (1970). British fournal of Radiology, 43, 31.

Maingot, R. (1956). In Operative Surgery, ed. C. Rob and R. Smith, vol. 2, p. 390 . London, Butterworth.

Marshall, N. W. (1970). British Fournal of Clinical Practice, 24, 25.

Price, W. H. (1963). British Medical Fournal, 2, 138.

Rhind, J. A., and Watson, L. (1968). British Medical Fournal, 1, 32.
Trafford, J. A. P., Fisher, A. M. H., Marshall, S., and Douthwaite, A. M. (1967). British fournal of Clinical Practice, 21, 457. 